\title{
Ventilator-associated events versus ventilator-associated respiratory infections - moving into a new paradigm or merging both concepts, instead?
}

\author{
Sergio Ramirez-Estrada ${ }^{1,2}$, Yolanda Peña-Lopez ${ }^{3}$, Vandana Kalwaje Eshwara ${ }^{4}$, Jordi Rello ${ }^{3,5}$ \\ ${ }^{1}$ Critical Care Department, Clínica Corachan, Barcelona, Spain; ${ }^{2}$ Medicine Department, Universitat Autónoma de Barcelona, (UAB), Barcelona, \\ Spain; ${ }^{3}$ Vall d'Hebron Institut of Research, Barcelona, Spain; ${ }^{4}$ Department of Microbiology, Kasturba Medical College, Manipal Academy of Higher \\ Education, Manipal, India; ${ }^{5}$ Centro de Investigación Biomédica en Red (CIBERES), Instituto Salud Carlos III, Madrid, Spain \\ Contributions: (I) Conception and design: None; (II) Administrative support: None; (III) Provision of study materials or patients: None; (IV) \\ Collection and assembly of data: None; (V) Data analysis and interpretation: None; (VI) Manuscript writing: All authors; (VII) Final approval of \\ manuscript: All authors. \\ Correspondence to: Sergio Ramírez-Estrada, MD. Clínica Corachan, Carrer de Buïgas, 19, 08017 Barcelona, Spain. Email: sergioramirezestrada@hotmail.com.
}

\begin{abstract}
Despite ventilator-associated respiratory infections (VARI) are reported as the most common and fatal complications related to mechanical ventilation (MV), they are not the unique occurrences. The new classification of ventilator-associated events (VAE) proposed by the centers for disease control and prevention (CDC) enhance the spectra of complications due to MV including both infection-related and non-infectious events. Both VAEs and VARIs are associated with prolonged duration of MV, longer stay in hospital and in the intensive care unit (ICU) and more antibiotic consumption, nonetheless patients with VAEs have worst outcomes. The VARI and VAE algorithms are focused on different targets and the correlation between both classifications is shown to be poor. The diagnostic criteria of the traditional classification have limited accuracy and the non-infectious complications may be misinterpreted as VARI. While the VAE surveillance enhances the spectra of MV complications but excludes less severe VARIs. Noninfective events explain up to $30 \%$ of VAEs, the main causes being atelectasis, acute respiratory distress syndrome, pulmonary edema and pulmonary embolism. The bundles assessing VAE are associated with less incidence of VAP and improved outcomes but they fail to reduce the rates of VAE. Automated VAE surveillance is efficient and useful as a quality indicator in the ICU while the differences in the interpretation of VARI criteria limit its role in the design of global protocols and preventive strategies. We suggest that a more comprehensive strategy should combine both algorithms with emphasis on clinical outcomes.
\end{abstract}

Keywords: Intensive care unit (ICU); mechanical ventilation (MV); ventilator-associated events (VAE); ventilatorassociated pneumonia (VAP); ventilator-associated respiratory infections (VARI)

Submitted Sep 15, 2018. Accepted for publication Oct 21, 2018.

doi: $10.21037 /$ atm.2018.10.54

View this article at: http://dx.doi.org/10.21037/atm.2018.10.54

\section{Introduction}

Since the first report in 1967 by Ashbaugh and Cols (1), the knowledge about the complications related to mechanical ventilation (MV) is constantly evolving. Traditionally the ventilator-associated respiratory infections (VARI) have been reported as the commonest complications of $\mathrm{MV}$ and there is a large body of literature assessing its clinical relevance and association with worse outcomes (2-4). Despite this, the complications of MV extend beyond the ventilator-associated pneumonia (VAP) and ventilatorassociated tracheobronchitis (VAT) and the role of noninfective events in mechanically ventilated patients is less known. In 2013, and later the MV complications 
were redefined by the Centres for Diseases Control and Prevention (CDC) $(5,6)$, the fraction of inspired oxygen $\left(\mathrm{FiO}_{2}\right)$ and the positive end expiratory pressure (PEEP) were incorporated as surrogated measures of hypoxemia, the chest radiograph was disregarded as diagnostic criteria and both infective and noninfective complications were included in the surveillance. The VAE surveillance $(5,6)$ divided MV complications into three tiers: (I) ventilator-associated condition (VAC), (III) infection-related ventilator-associated complication (IVAC), and (II) possible ventilator-associated pneumonia (PVAP). IVAC and PVAP were subsequently encompassed as IVAC-plus events in the latest update of VAE definitions (7). Detailed definitions of VARIs and VAEs are presented in the Table 1. The studies assessing VAE support its ability to detect noninfective complications and its good correlation with worse outcomes in both adult and paediatric patients but also highlight many undiagnosed VAPs and VATs $(8,10-13)$. In this review we discuss the advantages and disadvantages of both classifications.

\section{VAE, VARI and diagnostic criteria: strengths and weaknesses}

Although VAE and VARI classifications are designed to detect MV complications, both have different targets and use different diagnostic criteria. While VARI algorithm uses the chest X-Ray to classify the pulmonary infections, an unreliable and non-specific tool in ventilated patients, the VAE surveillance criteria disregard this test and redirect the focus on the respiratory worsening by monitoring the changes in two ventilator parameters: $\mathrm{FiO}_{2}$ and the PEEP. A detailed comparison between the pros and cons in both classifications is presented in Table 2.

\section{Chest X-ray}

While the chest X-ray is the cornerstone to diagnose VAP, its interpretation in the critically fill patient is limited $(13,31,32)$. Many complications such as ARDS, pulmonary edema, atelectasis and pulmonary embolism may be misinterpreted as respiratory infections by chest $\mathrm{X}$-ray $(12,32)$ and lead to an unnecessary antibiotic treatment. A potentially significant variation in perceived VAP rates has been reported depending on the frequency of other non-infective conditions by using a mathematical model in which the rate of VAP in an ICU is kept constant while the rates of other non-infective conditions are varied (15). On the other hand, the likelihood of VAP lowers to 0.35 in the absence of a new infiltrate on the chest X-ray (14) and most patients with possible VAP (PVAP) do not meet the $\mathrm{X}$-ray criteria for traditional VAP $(22,23)$. The exclusion of the radiological findings as diagnostic criteria increases the objectivity and comparability of VAE surveillance but limits its capability to detect less severe conditions as respiratory events in initial stages and some VATs, which could benefit from prompt antimicrobial treatment $(23,33)$.

\section{Clinical criteria}

Clinical criteria by CDC-2008 for VAP are nonspecific in ventilated patients. In fact, they have been using the same criteria for hospital-acquired pneumonia in nonventilated patients. Some of their clinical items are focused on detecting an increase in the work of breathing: cough, dyspnea, and tachypnea which have limited relevance in mechanically ventilated and sedated patients. As for patients subjected to spontaneous modes of ventilation, these items are highly variable depending on few ventilator setting parameters (pressure support, triggering) and a good clearance of respiratory secretions; Thus, it is difficult to differentiate between patient-ventilator dys synchrony and a real respiratory worsening by itself only through the criteria set in the definitions $(34,35)$. On the other hand, wheezing, rales and particularly bronchial sounds are frequently observed in ventilated patients due to a lack of secretion clearance. Finally, the worsening in gas exchange is not well defined.

In 2012 a simplified CDC-2008 criteria was proposed for ventilator-associated respiratory infections avoiding all the non-specific clinical criteria in ventilated patients, and including VAT and microbiological criteria (36). It is noteworthy that these simplified criteria included purulent secretions and provide objective data to define them. However, the respiratory worsening was not properly redefined and it continued to be a subjective item with different interpretations.

The VAE algorithm focuses primarily on the respiratory worsening as a key finding in the definition of VAC. Less severe episodes would be systematically excluded. On the other hand, in case of an infectious episode it shares with the old definition the more powerful clinical criteria by adding the condition of a minimum of 4 days of antimicrobial therapy thus avoiding inclusion of some noninfectious events that can mimic VARIs. This is a marked improvement compared to the previous definition but it continues to have some weaknesses in the new algorithm. 
Table 1 Comparison between ventilator-associated infection definitions $(5,6,8,9)$

\begin{tabular}{|c|c|c|c|c|}
\hline $\begin{array}{l}\text { Diagnostic } \\
\text { criteria }\end{array}$ & \multicolumn{2}{|r|}{$\mathrm{VARI}^{\mathrm{a}}(\mathrm{CDC} 2008)$} & \multicolumn{2}{|c|}{ Infective events of VAE (CDC 2013) } \\
\hline \multirow[t]{3}{*}{ Clinical } & Suspicion of infection ${ }^{g}$ & $\begin{array}{l}\text { One of the following: worsening gas } \\
\text { exchange }{ }^{k} \text {; tachypnea or dyspnea; } \\
\text { change in sputum characteristics'; } \\
\text { rales or bronchial breath sounds; } \\
\text { apnea in pediatric patients }\end{array}$ & $\begin{array}{l}\text { Increase in } \mathrm{FiO}_{2} \geq 0.20 \text { or } \\
\text { in } \mathrm{PEEP} \geq 3 \mathrm{cmH}_{2} \mathrm{O} \text { with a } \\
\text { previous period of stability } \\
\text { or improvement } \geq 2 \text { days }\end{array}$ & $\begin{array}{l}\text { Increase in } \mathrm{FiO}_{2} \geq 0.20 \\
\text { or in } \mathrm{PEEP} \geq 3 \mathrm{cmH}_{2} \mathrm{O} \\
\text { with a previous period of } \\
\text { stability or improvement } \\
\geq 2 \text { days }\end{array}$ \\
\hline & \multirow{2}{*}{$\begin{array}{l}\text { In infants } \leq 1 \text { year old: } \\
\text { respiratory distress; } \\
\text { apnea; bradycardia }^{h}\end{array}$} & \multirow{2}{*}{$\begin{array}{l}\text { And at least one: suspicion of } \\
\text { infection }^{g} \text {; altered mental status in } \\
\text { adults } \geq 70 \text { years old; bradycardia }^{\text {h or }} \\
\text { tachycardia }^{\mathrm{m}} \text { in infants } \leq 1 \text { year old }\end{array}$} & $\begin{array}{l}\text { And beginning of a new } \\
\text { antibiotic }\end{array}$ & $\begin{array}{l}\text { And beginning of a new } \\
\text { antibiotic }\end{array}$ \\
\hline & & & \multicolumn{2}{|c|}{$\begin{array}{l}\text { Pediatric patients: increase in } \mathrm{FiO}_{2} \geq 0.20 \text { or in PEEP } \\
\geq 1 \mathrm{cmH}_{2} \mathrm{O} \text { or increase in } \mathrm{FiO}_{2} \geq 0.15 \text { plus } \mathrm{PEEP} \\
\geq 1 \mathrm{cmH}_{2} \mathrm{O} \text { with a previous period of stability/ } \\
\text { improvement } \geq 1 \text { day }\end{array}$} \\
\hline \multirow[t]{2}{*}{ Chest X-ray } & \multirow[t]{2}{*}{$\begin{array}{l}\text { Absence of radiologic } \\
\text { criteria for pneumonia }\end{array}$} & $\begin{array}{l}\text { New or progressive infiltrate, } \\
\text { consolidation or cavitation }\end{array}$ & Not included & Not included \\
\hline & & Pneumatocele in infants $\leq 1$ year old & & \\
\hline \multirow[t]{3}{*}{ Microbiology } & \multirow[t]{3}{*}{$\begin{array}{l}\text { Purulent sputum }{ }^{i} \text { and } \\
\text { positive endotracheal } \\
\text { aspirate culture }\end{array}$} & $\begin{array}{l}\text { Significative growth of a pathogen in } \\
\text { respiratory samples }^{\text {j }}\end{array}$ & $\begin{array}{l}\text { Significative growth of a } \\
\text { pathogen in respiratory } \\
\text { samples }^{j}\end{array}$ & Not included \\
\hline & & $\begin{array}{l}>5 \% \text { Cells with intracellular bacteria in } \\
\text { bronchoalveolar lavage }\end{array}$ & $\begin{array}{l}\text { Insufficient growth of a } \\
\text { pathogenic microorganism } \\
\text { plus purulent sputumi }\end{array}$ & \\
\hline & & & $\begin{array}{l}\text { Positive test for Legionella } \\
\text { species }\end{array}$ & \\
\hline
\end{tabular}

g, suspicion of infection: fever $\left(\geq 38^{\circ} \mathrm{C}\right)$ or hypothermia $\left(\leq 36{ }^{\circ} \mathrm{C}\right)$ or leukocytosis $(\geq 12,000 \mathrm{cells} / \mathrm{mL}$ in adults or $\geq 15,000 \mathrm{cells} / \mathrm{mL}$ in $\leq 12$ years old ) or leukopenia ( $\leq 4,000$ cells $/ \mathrm{mL}$ ); ${ }^{\mathrm{h}}$, bradycardia in children $\leq 1$ year old: $<100$ beats per minute; ${ }^{i}$, purulent sputum: $\geq 25$ neutrophils with $<10$ squamous epithelial cells per low power field; ${ }^{j}$, significative growth in respiratory samples: endotracheal aspirate: $\geq 10^{5} \mathrm{CFU} / \mathrm{mL}$, bronchoalveolar lavage: $\geq 10^{4} \mathrm{CFU} / \mathrm{mL}$, lung tissue: $\geq 10^{4} \mathrm{CFU} / \mathrm{g}$, protected specimen brush: $\geq 10^{3} \mathrm{CFU} / \mathrm{mL}$; ${ }^{k}$, worsening gas Exchange: Increased oxygen requirements or in ventilator demand (mandatory criteria for infants $\leq 1$ year old); ', change in sputum characteristics: New onset of purulent respiratory secretions or increase in its production or in suctioning requirements; $\mathrm{m}$, tachycardia in infants $\leq 1$ year old: $>170$ beats per minute; ${ }^{n}$, histopathologic evidence of lung infection: abscess formation or foci of consolidation with intense polymorphonuclear accumulation or positive quantitative culture of parenchyma or evidence of parenchyma invasion by fungus or virus; ${ }^{\circ}$, in absence of other recognized focus. VARI, ventilator-associated respiratory infection; VAE, ventilatorassociated events; VAT, ventilator-associated tracheobronchitis; VAP, ventilator-associated pneumonia; PVAP, possible-ventilator associated pneumonia; IVAC-plus, infectious-ventilator associated complication plus. 
Table 2 PROS and CONS of VAE and VARI definitions

\begin{tabular}{lccc}
\hline PRO/CON & VAE & VARI & References \\
\hline Clinical correlation & +++ & ++ & $(14-17)$ \\
Physician-friendly concept & - & +++ & $(12,18,19)$ \\
Objectiveness (kappa index) & +++ & + & $(15,17,18,20,21)$ \\
Sensibility & - & ++ & $(11,12,22-24)$ \\
External comparability & +++ & +++ & $(15,25)$ \\
Diagnosis of VAT & - & +++ & $(8,10-12,22)$ \\
Diagnosis of VAP & - & - & $(8,10-13,17,22,23)$ \\
Non-infective events & +++ & ++ & $(2,8,12,21,24,26,27)$ \\
Impact on outcomes & $+++13,15)$ \\
Surveillance & +++ & ++ & $(25,28-30)$ \\
Quality indicator & +++ & + & $(11,21,25,30,31)$ \\
Histological findings & NA & + & $(9,14,16)$ \\
\hline
\end{tabular}

VAE, ventilator-associated event; VARI, ventilator-associated respiratory infection. +++, good; ++, fair; +, poor; -, none.

The use of early empiric antibiotics for the management of suspected sepsis and septic shock is a standard of care nowadays and is crucial for better clinical outcomes (37). Thus, it is easy to understand that, in clinical practice IVAC-plus will additionally include any respiratory worsening due to non-respiratory infections. Antimicrobial initiation might also be a response to an increase in acute phase reactants which cannot differentiate respiratory and non-respiratory focus of infection. Moreover, the rate of IVAC-plus will depend on the attending physician's decision to continue antibiotics for the next four days, strength of his clinical suspicion, the patient's clinical response, availability, speed and reliability of microbiological results $(38,39)$ and the antibiotic de-escalation policies of each centre $(20,40)$.

\section{Microbiological criteria}

There are few limitations in the interpretation of VARI diagnosis (41) in areas such as the role of quantitative cultures especially when not coupled with a respiratory worsening, and the nature respiratory samples are still a matter of controversy (9). Up to $44 \%$ of patients with VAP diagnosis do not have histological criteria of pneumonia $(16,17)$. In the VAE algorithm, some PVAP microbiological criteria are similar to VAP/VARI but its specificity increases because the criteria of respiratory worsening is fulfilled in all cases. Even though, some cases of PVAP can be misinterpreted due to previous colonization in patients with chronic and persistent purulent secretions and in those with other non-respiratory infection.

\section{Clinical correlation of VAE}

The first tier of the CDC-2013 algorithm, the VAC, explain up to $30 \%$ of VAEs in adults $(10,12)$ and about $45 \%$ in children (8), the main causes being atelectasis, ARDS, pulmonary edema, and pulmonary embolism $(4,12,24)$. They also are named in clinical practice as the non-infective events. Children differ from the adult population in that most of these VAC are due to atelectasis whilst frequent causes of VAC in adults are ARDS and pulmonary edema that are uncommon in the pediatric population $(26,42)$. This goes in line with the epidemiology of complications described in ventilated-children (43). On the other hand, these non-infective episodes are not considered in the VARI classification but frequently they are misdiagnosed as VAP due to the misinterpretation of chest $\mathrm{X}$-ray, as it has been pointed earlier.

At this point, it should be noted that some confusion has been generated in the literature due to the inappropriate application of the terms designed by the CDC. Frequently VAE are referred as VAC while VAC include only those events with respiratory worsening. While it is true that all VAE (VAC, IVAC, and PVAP) meet criteria for VAC, the 
term VAC is reserved only for those events with respiratory worsening thus excluding IVAC and PVAP events. VAE and not VAC, encompasses VAC, IVAC and PVAP. The different tiers of VAE should be cautiously interpreted while studying and interpreting the clinical correlations and outcomes.

The second tier of the CDC-2013 algorithm, the infection-related ventilator-associated complications (IVAC) was designed to detect those respiratory worsening due to an infectious agent but not microbiologically confirmed as respiratory origin. Thus, it refered to those respiratory conditions possibly leading to sepsis excluding probable ventilator-associated pneumonia. Once again, there has been some confusion in the use of the term IVAC in the scientific literature. Most studies referred to it as the sum of IVAC and probable VAP (PVAP). The last update of the new algorithm solved this problem adding a new concept in the algorithm: the IVAC-plus events.

Finally, the third tier of the new algorithm, the probable ventilator-associated pneumonia (PVAP) seemed to resolve confusions about VAP. It has a good negative predictive value but its sensitivity is low thus excluding most VAP. On the other hand, in case of electronic surveillance, it is possible to misclassify any respiratory worsening as PVAP in patients with previous airway colonization when the antibiotic policy of the hospital is weak.

\section{Clinical correlation of VARI}

The VARI classification is widely recognized by the health care professionals and its association with worse clinical outcomes is well known $(2,4,27)$. It has long been considered the standard of diagnosis of the respiratory infections related to MV $(2,4,18)$. Sometimes the clinical and radiologic criteria for VARI can be explained by more than one cause including non-infective conditions $(10,12)$, the prevalence of VAP can increase up to 5 -fold depending on the frequency of noninfective complications as ARDS, atelectasis or pulmonary edema due to a misinterpretation of the $\mathrm{X}$-chest ray (15). Due to subjectivity in the interpretation of the chest $\mathrm{X}$-ray and in the clinical manifestations, the inter-observer variability when the VARI diagnostic algorithm is used is high (Kappa 0.4) $(14,17)$. As a result, the real incidence of VARIs is not clear (18). Even the anatomopathological studies taking the autopsy and the lung biopsy findings as gold standard, up to $44 \%$ of patients with VAP diagnosis did not have histological criteria of pneumonia $(14,16)$.

\section{Ventilator-associated tracheobronchitis (VAT)}

In the recent years there is accumulating evidence supporting VAT as a clinically important nosocomial infection by its own right in children and adults with different impact on outcomes compared to VAP (9,44-47). Although VAT and VAP may overlap, these are two newly recognised different conditions. On one hand, the adequate antimicrobial treatment of VAT has demonstrated to protect against the development of subsequent VAP and decreased MV days and ICU stay $(44,45,47,48)$. On the other hand, in clinical practice not all VAP are preceded by VAT and not all VAT progress to $\operatorname{VAP}(45,47,48)$. Additionally, few translational researchers have reported different patterns of microbiome and adaptive responses when comparing VAT and VAP $(49,50)$. Thus, a new entity is ensuing in the coming years and the need for antibiotic prescription is a hot topic in those patients.

\section{Clinical correlation between VARI and VAE}

A poor correlation between VAP and VAE is supported by several studies. This seems logical as both VAP and VAE have different targets, as discussed above. Maybe the designation of VAE as the "new CDC definition of VAP" has arisen confusion about the new concept and strong rejection by some authors. While it's obvious that VAP is not the same as VAE, there is an increased interest in VAE due to its inclusion of diverse complications related to mechanical ventilation. Studies comparing both VARI versus VAE report an increase in the rate of complications when the new criteria are assessed $(10,12,24)$, which was expected; however, in a meta-analysis (24) including more than 6,000 patients, VAE failed to detect VAP in almost $50 \%$ of cases. Despite excluding non-infectious complications among VAE, the rates of PVAP and even IVAC-plus rates were lower than traditional VARI $(12,24)$. Two retrospective analysis assessing complications of mechanical ventilation in both European (10) and North American (11) ICUs reported that those patients who had IVAC-plus were more likely to be diagnosed with VAP but a significant number of VAP were not diagnosed as IVAC-plus.

Moreover, diagnosis of VAT has been omitted in the VAE algorithm, although it could be included in the PVAP tier. In the European VAE surveillance multicentric study 1/3rd of adult mechanically ventilated patients developed VARIs, $60 \%$ of them were due to VAT (29.3 per 1,000 ventilatory 
days) but only $25 \%$ of those VAT achieved VAE criteria (12). A significant percentage of cases of VAP without the time frame required by the VAE classification have been reported in medical $(71 \%)$ and traumatic $(82 \%)$ patients $(22,51)$, interestingly these rate decreases to $39 \%$ in surgical ICUs. Additionally, some series report a negative predictive value for VAE and PVAP nearly to $100 \%(12,22,24)$.

Thus, the VAE classification only detects those complications severe enough to produce a sustained respiratory worsening and almost $25 \%$ of VARI can be missed $(10,12,22,24)$, most of them by not fulfilling the time frame required by the VAE classification $(22,51)$. Because of it, the power of the VAE algorithm to detect VAT is limited too. Interestingly, a recent study in children found a fourfold increase in VAEs and the double of PVAP when less restrictive criteria for respiratory worsening were employed, and keeping the repercussion on outcomes of this less restrictive VAE definition when compared with traditional VARI criteria (8).

\section{VAE, VARI and surveillance}

The reports about VARI incidence are highly variable with rates between 2 and 18 episodes per 1,000 ventilator days $(9,19,52-54)$ and surprisingly, in some series the prevalence of VAP is zero $(24,55)$. In contrast, the VAE algorithm was designed to define more objective and comparable criteria and to enhance the spectra of complications related to MV. The lack of consensus limits the role of VARI in the design of global protocols and preventive strategies. While the VARI criteria are difficult to quantify and compare, the VAE paradigm is measurable, reproducible and its implementation in automated surveillance programs reduce the time spent by more than $90 \%$ with higher sensitivity and specificity $(28,29)$ along with being a good quality indicator for benchmarking in the ICUs $(25,30,31)$.

\section{VARI and VAE risk factors and prevention}

Despite a growing body of knowledge, the role of risk factor and its prevention in the development of VAE is not completely understood particularly in adults where the evidence is weak or controversial $(31,56,57)$. The length of MV is a limiting factor for the development of both VARIs and VAEs therefore early weaning practices including spontaneous breathing, daily awakening trials and an adequate control of pain are highly advised $(31,58)$. Deep and prolonged sedation is correlated with more MV days and worst outcomes $(31,59)$. The use of long-term sedatives, opioids, paralytic medications and mandatory modes of ventilation were reported as possible risk factors for IVAC-plus (60); in a recent study (61) assessing sedative exposure in patients under MV, the use of benzodiazepines was associated with less MV-free days and increased risk to develop VAE than dexmedetomidine or propofol, additionally dexmedetomidine was also associated with less time to extubation when compared with propofol. The role of spontaneous breathing trial and spontaneous awakening trial in the prevention of VAE is controversial $(57,60,62,63)$. A positive fluid balance (64-66) is independently associated with worse outcomes in the ventilated patients especially in those with or at risk for ARDS and its association with VAP is widely reported in the literature (31,67-69); each litre of fluid accumulated increases up to 1.2 the risk of developing any kind of VAE (60). There is a reasonable evidence that protective ventilation help to prevent VAE due its association with lower rates of ARDS, VARI and atelectasis (70-72); observational data suggest that patients with VAEs are more likely to be ventilated with a nonprotective strategy $(56,60)$, the use of mandatory modes of ventilation can increase the rate of VAC by increasing patient-ventilator dys-synchrony and ventilator induced lung injury (VILI) (60), however prospective studies in the field are needed $(56,73)$. The use of bundles of care including semi recumbent positioning, venous thromboembolism prophylaxis and stress ulcer prophylaxis were proven to reduce the incidence of VAP in the past (10,74-77), but they are not able to decrease the incidence of VAEs $(31,62,78)$. Furthermore, in a recent study the oral care with chlorhexidine was associated with a greater risk for VAE development. Finally, in pediatric patients risk factors for developing VAEs include immunocompromised status, tracheostomy dependence, and chronic respiratory disease (21), while the presence of acute kidney injury, prolonged ventilatory support, and neuromuscular blockade were associated with an increased risk for IVAC (79).

\section{Conclusions}

The VARI and VAE classifications help to assess the ventilator-associated complications however remain to be fully elucidated. Both classifications focus on different targets, the VARI algorithm detect respiratory infection and differentiates between VAP and VAT but many noninfective-related complications also can achieve VARI criteria. The VAE surveillance enhances the spectra of MV 
complications including non-infective events and select only the most severe cases whereas many VAP and VAT are dismissed. We suggest a better strategy that should combine both algorithms with the incorporation of clinical outcomes. Further studies should assess the applicability of biomarkers of pulmonary infection and molecular diagnostic techniques in the MV complications and the design of protocols incorporating the bedside thoracic ultrasound.

\section{Acknowledgements}

This article was carried out as part of a $\mathrm{PhD}$ program in Health Science, in the Department of Medicine, at the Universitat Autónoma de Barcelona. Supported in part by a grant (PCI Pneumonia) from CIBERES, Instituto Salud Carlos III, Madrid, Spain.

\section{Footnote}

Conflicts of Interest: The authors have no conflicts of interest to declare.

\section{References}

1. Ashbaugh DG, Bigelow DB, Petty TL, et al. Acute respiratory distress in adults. Lancet 1967;2:319-23.

2. Macht M, Robinson JC, Graham BB. Updated approach for the assessment of ventilator-associated pneumonia. Crit Care Med 2013;41:2641-2.

3. Rello J, Diaz E, Mañez R, et al. Improved survival among ICU-hospitalized patients with community-acquired pneumonia by unidentified organisms: a multicenter case-control study. Eur J Clin Microbiol Infect Dis 2017;36:123-30.

4. Melsen WG, Rovers MM, Groenwold RHH, et al. Attributable mortality of ventilator-associated pneumonia: a meta-analysis of individual patient data from randomised prevention studies. Lancet Infect Dis 2013;13:665-71.

5. Center for Disease Control and Prevention [Internet]. Ventilator-associated event; c2018 [cited 2018 jun 18]. Available online: http://www.cdc.gov/nhsn/pdfs/ pscmanual/10-vae_final.pdf

6. Magill SS, Klompas M, Balk R, et al. Developing a new national approach to surveillance for ventilatorassociated events: Executive summary. Am J Infect Control 2013;41:1096-9.

7. Magill SS, Rhodes B, Klompas M. Improving ventilatorassociated event surveillance in the National Healthcare
Safety Network and addressing knowledge gaps: update and review. Curr Opin Infect Dis 2014;27:394-400.

8. Peña-López Y, Pujol M, Campins M, et al. Assessing prediction accuracy for outcomes of ventilator-associated events and infections in critically ill children: a prospective cohort study. Clin Microbiol Infect 2018;24:732-7.

9. Torres A, Niederman MS, Chastre J, et al. International ERS/ESICM/ESCMID/ALAT guidelines for the management of hospital-acquired pneumonia and ventilator-associated pneumonia: Guidelines for the management of hospital-acquired pneumonia (HAP)/ ventilator-associated pneumonia (VAP) of the European Respiratory Society (ERS), European Society of Intensive Care Medicine (ESICM), European Society of Clinical Microbiology and Infectious Diseases (ESCMID) and Asociación Latinoamericana del Tórax (ALAT). Eur Respir J 2017;50:3.

10. Muscedere J, Sinuff T, Heyland DK, et al. The clinical impact and preventability of ventilator-associated conditions in critically ill patients who are mechanically ventilated. Chest 2013;144:1453-60.

11. Bouadma L, Sonneville R, Garrouste-Orgeas M, et al Ventilator-Associated Events: Prevalence, Outcome, and Relationship With Ventilator-Associated Pneumonia. Crit Care Med 2015;43:1798-806.

12. Ramírez-Estrada S, Lagunes L, Peña-López Y, et al. Assessing prediction accuracy for outcomes of ventilator associated events in an international cohort: The EUVAE study. Intensive Care Med 2018;44:1212-20.

13. He S, Wu F, Wu X, et al. Ventilator-associated events after cardiac surgery: evidence from 1,709 patients. J Thorac Dis 2018;10:776-83.

14. Klompas M. Does this patient have ventilator-associated pneumonia?. JAMA 2007;297:1583-93.

15. Klompas M, Kulldorff M, Platt R. Risk of misleading ventilator-associated pneumonia rates with use of standard clinical and microbiological criteria. Clin Infect Dis 2008;46:1443-6.

16. Tejerina E, Esteban A, Fernández-Segoviano P, et al. Accuracy of clinical definitions of ventilator-associated pneumonia: comparison with autopsy findings. J Crit Care 2010;25:62-8.

17. Klompas M. Interobserver variability in ventilatorassociated pneumonia surveillance. Am J Infect Control 2010;38:237-9.

18. Pearson D, Hayashi Y, Richards B, et al. VAP, VAC, IVAC, and ventilator-associated events: the need for objectivity for surveillance. ICU Management \& Practice. [internet]. 
2014 dec [cited 2018 june 17]. Available online: https:// healthmanagement.org/c/icu/issuearticle/vap-vac-ivacand-ventilator-associated-events-the-need-for-objectivityfor-surveillance.

19. Stoeppel CM, Eriksson EA, Hawkins K, et al. Applicability of the National Healthcare Safety Network's surveillance definition of ventilator-associated events in the surgical intensive care unit: a 1-year review. J Trauma Acute Care Surg 2014;77:934-7.

20. Silva BN, Andriolo RB, Atallah AN, et al. De-escalation of antimicrobial treatment for adults with sepsis, severe sepsis or septic shock. Cochrane Database Syst Rev 2013;28:CD007934.

21. Phongjitsiri S, Coss-Bu J, Kennedy C, et al. The Centers for Disease Control and Prevention's New Definitions for Complications of Mechanical Ventilation Shift the Focus of Quality Surveillance and Predict Clinical Outcomes in a PICU. Crit Care Med 2015;43:2446-51.

22. Lilly CM, Landry KE, Sood RN, et al. Prevalence and test characteristics of national health safety network ventilatorassociated events. Crit Care Med 2014;42:2019-28.

23. Pugh R, Harrison W, Harris S, et al. Is HELICS the Right Way? Lack of Chest Radiography Limits VentilatorAssociated Pneumonia Surveillance in Wales. Front Microbiol 2016;7:1271.

24. Fan Y, Gao F, Wu Y, Zhang J, et al. Does ventilatorassociated event surveillance detect ventilator-associated pneumonia in intensive care units? A systematic review and meta-analysis. Crit Care 2016;20:338.

25. Hebert C, Flaherty J, Smyer J, et al. Development and validation of an automated ventilator-associated event electronic surveillance system: A report of a successful implementation. Am J Infect Control 2018;46:316-21.

26. Rello J, Peña-López Y, Solé-Violan. Implications of oxygenation variations in ventilated patients with respiratory infections. Minerva Anestesiol 2018;84:423-5.

27. Phu VD, Nadjm B, Duy NHA, et al. Ventilator-associated respiratory infection in a resource-restricted setting: impact and etiology. J Intensive Care 2017;5:69.

28. Nuckchady D, Heckman MG, Diehl NN, et al. Assessment of an automated surveillance system for detection of initial ventilator-associated events. Am J Infect Control 2015;43:1119-21.

29. Mann T, Ellsworth J, Huda N, et al. Building and Validating a Computerized Algorithm for Surveillance of Ventilator-Associated Events. Infect. Control Hosp Epidemiol 2015;36:999-1003.

30. Shenoy ES, Rosenthal ES, Shao YP, et al. Real-Time,
Automated Detection of Ventilator-Associated Events: Avoiding Missed Detections, Misclassifications, and False Detections Due to Human Error. Infect Control Hosp Epidemiol 2018;39:826-33.

31. Rello J, Peña-López Y, Ramirez-Estrada S, et al. Limiting complications associated with ICU intubation. Expert Rev Resp Med. Forthcoming 2018.

32. Klompas M, Kalil, AC. Rethinking Ventilator Bundles. Crit Care Med 2018;46:1201-3.

33. Nseir S, Martin-Loeches I, Makris D, et al. Impact of appropriate antimicrobial treatment on transition from ventilator-associated tracheobronchitis to ventilatorassociated pneumonia. Crit Care 2014;18:R129.

34. Pham T, Telias I, Piraino T,et al. Asynchrony Consequences and Management. Crit Care Clin 2018;34:325-41.

35. Vaporidi K, Babalis D, Chytas A, et al. Clusters of ineffective efforts during mechanical ventilation: impact on outcome.Intensive Care Med 2017;43:184-91.

36. Klompas M, Kleinman K, Khan Y, et al. Rapid and reproducible surveillance for ventilator-associated pneumonia. Clin Infect Dis 2012;54:370-7.

37. Rhodes A, Evans LE, Alhazzani W, et al. Surviving Sepsis Campaign: International Guidelines for Management of Sepsis and Septic Shock: 2016. Intensive Care Med 2017;43:304-77.

38. Buehler SS, Madison B, Snyder SR, et al. Effectiveness of Practices To Increase Timeliness of Providing Targeted Therapy for Inpatients with Bloodstream Infections: a Laboratory Medicine Best Practices Systematic Review and Meta-analysis. Clin Microbiol Rev 2016;29:59-103.

39. Jeverica S, Nagy E, Mueller-Premru M, et al. Sample preparation method influences direct identification of anaerobic bacteria from positive blood culture bottles using MALDI-TOF MS. Anaerobe 2018. [Epub ahead of print].

40. Luyt CE, Bréchot N, Trouillet JL, et al. Antibiotic stewardship in the intensive care unit. Crit Care 2014;18:480.

41. Kerlin MP, Trick WE, Anderson DJ, et al. Interrater Reliability of Surveillance for Ventilator-Associated Events and Pneumonia. Infect Control Hosp Epidemiol 2017;38:172-8.

42. Cocoros NM, Priebe GP, Logan LK, et al. A Pediatric Approach to Ventilator-Associated Events Surveillance. Infect Control Hosp Epidemiol 2017;38:327-33.

43. Principi T, Fraser DD, Morrison GC, et al. Complications of mechanical ventilation in the pediatric population. 
Pediatr Pulmonol 2011;46:452-7.

44. Nseir S, Favory R, Jozefowicz E, et al. Antimicrobial treatment for ventilator-associated tracheobronchitis: a randomized controlled multicenter study. Crit Care 2008;12:R62.

45. Cantón-Bulnes ML, Gonzalez-Garcia MA, GarciaSanchez M, et al. A case-control study on the clinical impact of ventilator associated tracheobronchitis in adult patients who did not develop ventilator associated pneumonia. Enferm Infecc Microbiol Clin 2018. [Epub ahead of print].

46. Karvouniaris M, Makris D, Manoulakas E, et al. Ventilator-Associated Tracheobronchitis Increases the Length of Intensive Care Unit Stay. Infect Control Hosp Epidemiol 2013;34:800-8.

47. Martin-Loeches I, Povoa P, Rodríguez A, et al. TAVeM study. Incidence and prognosis of ventilator-associated tracheobronchitis (TAVeM): a multicentre, prospective, observational study. Lancet Respir Med 2015;3:859-68.

48. Agrafiotis M, Siempos II, Falagas ME. Frequency, prevention, outcome and treatment of ventilator-associated tracheobronchitis: Systematic review and meta-analysis. Respir Med 2010;104:325-36.

49. Roux D, van Oort PM, Ricard JD, et al. Airway microbiome research: a modern perspective on surveillance cultures?. Ann Transl Med 2017;5:445.

50. Martin-Loeches I, Papiol E, Almansa R, et Al. Intubated patients developing tracheobronchitis or pneumonia have distinctive complement system gene expression signatures in the pre-infection period: a pilot study. Med Intensiva 2012;36:257-63.

51. Piriyapatsom A, Lin H, Pirrone M, et al. Evaluation of the Infection-Related Ventilator-Associated Events Algorithm for Ventilator-Associated Pneumonia Surveillance in a Trauma Population. Respir Care 2016;61:269-76.

52. Beardsley AL, Nitu ME, Cox EG, et al. An Evaluation of Various Ventilator-Associated Infection Criteria in a PICU. Pediatr. Crit Care Med 2016;17:73-80.

53. Wałaszek M, Różańska A, Wałaszek MZ, et al. Epidemiology of Ventilator-Associated Pneumonia, microbiological diagnostics and the length of antimicrobial treatment in the Polish Intensive Care Units in the years 2013-2015. BMC Infect Dis 2018;18:308.

54. Bonell A, Azarrafiy R, Huong VTL, et al. A systematic review and meta-analysis of ventilator associated pneumonia in adults in Asia; an analysis of national income level on incidence and etiology. Clin Infect Dis 2018. [Epub ahead of print].
55. Dudeck MA, Weiner LM, Allen-Bridson K, et al. National Healthcare Safety Network (NHSN) report, data summary for 2012, device-associated module. Am J Infect Control 2013;41:1148-66.

56. Klompas M. Potential Strategies to Prevent Ventilatorassociated Events. Am J Respir Crit Care Med 2015;192:1420-30.

57. Cocoros NM, Klompas M. Ventilator-Associated Events and Their Prevention.Infect Dis Clin North Am 2016;30:887-908.

58. Bounds M, Kram S, Speroni KG, et al. Effect of ABCDE Bundle Implementation on Prevalence of Delirium in Intensive Care Unit Patients. Am J Crit Care 2016;25:535-44.

59. Ouellette DR, Patel S, Girard TD, et al. Liberation From Mechanical Ventilation in Critically Ill Adults: An Official American College of Chest Physicians/American Thoracic Society Clinical Practice Guideline: Inspiratory Pressure Augmentation During Spontaneous Breathing Trials, Protocols Minimizing Sedation, and Noninvasive Ventilation Immediately After Extubation. Chest 2017;151:166-80.

60. Lewis SC, Li L, Murphy MV, et al. Risk Factors for Ventilator-Associated Events: A Case-Control Multivariable Analysis. Crit care med 2014;42:1839-48.

61. Klompas M, Li L, Szumita P, et al. Associations Between Different Sedatives and Ventilator-Associated Events, Length of Stay, and Mortality in Patients Who Were Mechanically Ventilated. Chest 2016;149:1373-9.

62. O'Horo JC, Lan H, Thongprayoon C, et al. "Bundle" Practices and Ventilator-Associated Events: Not Enough. Infect Control Hosp Epidemiol 2016;37:1453-7.

63. Rawat N, Yang T, Ali KJ, et al. Two-State Collaborative Study of a Multifaceted Intervention to Decrease Ventilator-Associated Events. Crit Care Med 2017;45:1208-15.

64. Wiedemann HP, Wheeler AP, Bernard GR, et al. Comparison of two fluid-management strategies in acute lung injury. N Engl J Med 2006;354:2564-75.

65. Rosenberg AL, Dechert RE, Park PK, et al. Review of a large clinical series: association of cumulative fluid balance on outcome in acute lung injury: a retrospective review of the ARDSnet tidal volume study cohort. J Intensive Care Med 2009;24:35-46.

66. Alobaidi R, Morgan C, Basu RK, et al. Association Between Fluid Balance and Outcomes in Critically Ill Children: A Systematic Review and Meta-analysis. JAMA Pediatr 2018;172:257-68. 
67. American Thoracic Society, Infectious Diseases Society of America. Guidelines for the management of adults with hospital-acquired, ventilator-associated, and healthcareassociated pneumonia. Am J Respir Crit Care Med 2005;171:388-416.

68. Mekontso Dessap A, Katsahian S, Roche-Campo F, et al. Ventilator-associated pneumonia during weaning from mechanical ventilation: Role of fluid management. Chest 2014;146:58-65.

69. Forel JM, Voillet F, Pulina D, et al. Ventilator-associated pneumonia and ICU mortality in severe ARDS patients ventilated according to a lung-protective strategy. Crit Care 2012;16:R65.

70. Slutsky AS, Ranieri VM. Ventilator-induced lung injury. N. Engl. J. Med. 2013;369:2126-36.

71. Biehl M, Kashiouris MG, Gajic O. Ventilator-Induced Lung Injury: Minimizing Its Impact in Patients With or at Risk for ARDS. Respir Care 2013;58:927-37.

72. Briel M, Meade M, Mercat A, et al. Higher vs Lower Positive End-Expiratory Pressure in Patients With Acute Lung Injury and Acute Respiratory Distress Syndrome: Systematic Review and Meta-analysis. JAMA 2010;303:865-73.

73. Serpa Neto A, Cardoso SO, Manetta JA, et al. Association

Cite this article as: Ramirez-Estrada S, Peña-Lopez Y, Kalwaje Eshwara V, Rello J. Ventilator-associated events versus ventilator-associated respiratory infections-moving into a new paradigm or merging both concepts, instead? Ann Transl Med 2018;6(21):425. doi: 10.21037/atm.2018.10.54 between use of lung-protective ventilation with lower tidal volumes and clinical outcomes among patients without acute respiratory distress syndrome: a meta-analysis. JAMA 2012;308:1651-9.

74. Klompas M, Anderson D, Trick W, et al. The preventability of ventilator associated events. The CDC Prevention Epicenters Wake Up and Breathe Collaborative. Am J Respir Crit Care Med 2015;191:292-301.

75. Pileggi C, Mascaro V, Bianco A, et al. Ventilator Bundle and Its Effects on Mortality Among ICU Patients: A MetaAnalysis. Crit Care Med 2018;46:1167-74.

76. Rello J, Lode H, Cornaglia G, et al. A European care bundle for prevention of ventilator-associated pneumonia. Intensive Care Med 2010;36:773-80.

77. Rello J, Afonso E, Lisboa T, et al. A care bundle approach for prevention of ventilator-associated pneumonia. Clin Microbiol Infect 2013;19:363-9.

78. Harris BD, Thomas GA, Greene MH, et al. Ventilator Bundle Compliance and Risk of Ventilator-Associated Events. Infect Control Hosp Epidemiol 2018;39:637-43.

79. Guess R, Vaewpanich J, Coss-Bu JA, et al. Risk Factors for Ventilator-Associated Events in a PICU. Pediatr Crit Care Med 2018;19:e7-13. 